\title{
Seizing the Digital
}

\author{
JANET VERTESI ${ }^{1}$ \\ PRINCETON UNIVERSITY
}

\begin{abstract}
Digital systems pervade classic STS sites of interest, from connecting laboratories to mediating lay-expert divides. But STS has so far been reticent to build the theoretical and analytical perspectives necessary for embracing digital systems as an important element of contemporary fieldwork, research, and practice. This paper charts a course for bringing STS concepts to bear on digital systems and vice versa, bringing our lingering concern with questions from the sociology of knowledge to bear on digitally-enacted and mediated scientific and technical practices. It shows how we can eschew the language of technological determinism inherent to discussion about digital systems outside of STS, asking instead questions germane to STS theory and practice such as the configuration of such systems to include and exclude, the epistemic entanglements of using digital tools in research practice, and the potential to build new systems that suggest alternative arrangements.
\end{abstract}

\section{Keywords}

digital systems; information technology; laboratory studies making; STS

\section{Introduction}

As a scholar, I grew up with STS. I took my first class in history and philosophy of science as a second year undergraduate. Twenty years later, I hold three advanced degrees in the topic, have

\footnotetext{
1 Janet Vertesi, Email: jvertesi@princeton.edu

Copyright (C) 2016 (Janet Vertesi). Licensed under the Creative Commons Attribution Non-commercial No Derivatives (bync-nd). Available at estsjournal.org.
} 
studied with foundational figures in the field at Cambridge University's History and Philosophy of Science department and at Cornell University's Science \& Technology Studies department, and wrote a dissertation that was a classic laboratory ethnography. I've long since rejected technological determinism or Whig historicism in favor of the wide variety of perspectives on the sociology of science, knowledge, and technology developed in this community. Yet in the past few years, I have come to realize that this sort of biographical prelude is important once I start talking about urgency of addressing "the digital" in science and technology studies.

On the one hand, this is no doubt because of the enthusiasm and revolutionary rhetoric that the term engenders. Technological utopianism is alive and well in the globally outsourced products of Silicon Valley. Digital objects and devices are overhyped: shiny and obsolete as soon as they emerge from the factory, embedded in a relentless narrative of technological progress with little room for critique. On the other hand, I frequently hear the STS concern that we forget our history in a race to embrace "the digital." This is both because STS more typically investigates continuities of practice and of power relations embedded in technologies that are otherwise hailed as "revolutionary," and because members of our community have been studying digital systems and practices for some time now (i.e. Lynch 1991; Suchman 1987; Woolgar 1990). Both in terms of our empirical field sites and our analytical work, a much-hyped term like "the digital" must be something good STS scholars should avoid.

Like many in the field, I am fiercely skeptical of "the digital" and its attendant claims to novelty. Yet as a laboratory ethnographer I cannot deny that the textures--or what Michael Lynch calls the "topical contextures" (Lynch 1991)—of laboratory life have shifted in the past twenty years. Laboratories have increasingly expanded through fiber optic networks and shared databases to include a variety of "remote" locations, distributing "centers of calculation" across sites and troubling ongoing distinctions between center and periphery. Lab meetings happen by teleconference call, Skype, and WebEx; lab gossip circulates on Facebook; references to backroom Twitter chatter at conferences permeate conversation. Scientists sit at professional meetings with their Bluetooth headsets blinking through the talks, simultaneously "co-present" on a conference call and in the room (Beaulieu 2010; Vertesi 2014).

Scientific analytics are increasingly in silico too. In my work with planetary scientists I still see the occasional traditional laboratory where equipment and technicians compress air at low density and temperatures to approximate conditions on other planets. More frequently, however, I watch as scientists manipulate digital images and apply algorithmic functions to data plots, pointing to pixels on their screens as traces of photons captured by instruments millions of miles away. Other elements of laboratory life have shifted uneasily too. Twenty-first century 
"norms" of science (Merton 1942) must now contend with open datasets, shared code repositories, and Google Scholar citation counts, each with its associated tensions and counternorms in practice. Where Latour and Woolgar (1979) once postulated that the laboratory exists to turn rats into paper, contemporary laboratories turn rats into PowerPoint slides.

In all this, many elements dear to the heart of STS scholars remain the same. Credit, instrumentation and instrumental practices still matter, as do circulation of "inscriptions" (Latour 1988). There is still place (Gieryn 2002; Kohler 2002), sense-making (Lynch 1993), epistemic cultures (Knorr-Cetina 1999), the reproduction of inequalities (Bowker and Star 1999), and "centers of calculation" (Latour 1988) that produce peripheries and privilege particular ways of knowing — and knowledge makers (Haraway 1988). Yet this shift in topical contexture requires our attention in our empirically-grounded theorizing, in our methods, and in our interventions. In particular, as scholars concerned with questions of epistemography (Dear 2001) or even with ontography (Lynch 2013) it requires our attention, and to do so, our renewed engagement with related fields.

\section{Digital Fieldsites}

Anyone studying a laboratory these days will tell you that computers, smart phones, sensors, and chips are ubiquitous. They recede into the background as familiar everyday objects, even as they are the place where knowledge work is accomplished. Along with them the role of the ethnographer shifts, with the networked connectivities of these labs requiring the full sense of Marcus' analytic term, "multi-sitedness" (1995). Following Beaulieu's encouragement of "copresence" (2010) ethnographers must seemingly be everywhere at once. They must befriend their participants on Facebook and experience laboratory life on many sides of a teleconference line or Skype call. They must analyze software and hardware techniques the way we have analyzed DNA gels and fingerprinting (Jordan and Lynch 1998; Lynch et al 2008). They must be attuned to chatter from lay experts who now interact directly with scientists online, participate in digital fora, and mobilize through Twitter.

To grapple with these early twenty-first century elements of scientific, technical, and political life, we must engage with sociological theories of information technologies in everyday contexts. We are late to this party. The scholarship that already defines much of this analytic space has a heritage in media studies and human-computer interaction. In many cases, this scholarship follows the path of STS scholars who have engaged outside the discipline with communication, design, or computer-supported cooperative work (Boczwowski and Foot, 2014; Berg 1998; 
Jackson et al. 2011). That STS tools and scholars are traveling afield is a positive development. After all, scholarship in these cross-over domains now explores how artifacts have politics (Winner, 1986) and use the concept of "boundary objects" (Star and Griesemer 1998; albeit often without a sense of the debates that followed such elements in STS, as in: Woolgar and Cooper 1999; Latour 2004; Star 2010). However, we need to bring these conversations about information technology "back home" to our own inter-discipline as well, to expand our own analytical toolkits.

We might take the lead from examples of studies of digital financial markets at the intersection of economic sociology and STS (i.e. MacKenzie 2006; Knorr-Cetina and Bruegger 2000; Knorr-Cetina and Preda 2005; Stark 2009); this work has not only affected our understanding of trading systems but also challenged our theoretical tools and commitments in STS as well. And studies of computational knowledge infrastructures inspired by the early work of Leigh Star (Star and Ruhleder 1994; Bowker and Star 1999) has had cross-over impact in both computer science fields and science studies (i.e. see Bietz et al. 2010; Edwards 2013; Ribes and Bowker 2008; Millerand et al. 2013). However, this project cannot be limited to specific domains such as finance or research computing: it must expand to include digital tools and software wherever we find them in our field sites.

We should not shy away from this expansion. After all, STS has defined a way of talking about technology in social context and in social life that is distinct from the perspectives of media scholarship or computer-supported cooperative work. From co-construction to actor networks, infrastructures to ontologies, social constructivism to standpoint theory, STS theories make different assumptions about what we are talking about when we talk about "technology" and its human entanglements, what matters and how it matters in the phenomenal field. We have a robust toolset already developed in conversation with history, philosophy, anthropology, and sociology of science and technology to analyze work and life among digital systems. This voice and these interdisciplinary engagements are necessary to effect a broader conversation among social scientists about digitality, digital objects, and contemporary social change.

We are especially well placed to contribute to this conversation because STS brings a lingering concern with questions from the sociology of knowledge to bear on these contemporary scientific and technical practices. Thus, our questions in this space are not and should not be, "How are digital technologies changing social life?" - a form of technological determinism that surfaces among media pundits. Instead, we might ask: whose ways of knowing are written into these ever-expanding technological systems, with what privilege, and whose ways of knowing are left out? And how do such systems act upon us to reproduce these systematic distinctions, 
categorizations, inequalities, and hierarchies? Further, while the majority of academic studies in media and information science literatures focus on individual digital systems like Facebook or MySpace, we can deploy a vocabulary of heterogeneity, hybrids, infrastructures and networked ontologies to expand the definition of "social context" in which such information and communication technologies operate.

In addition, there are a wide range of scenarios surrounding the contemporary deployment of digital systems that present real-world implications for justice and social life. For instance, Sarah Brayne's qualitative studies of predictive policing show how algorithmic data analysis produces maps of where predicted criminal activity will occur in a large US city drawing upon "big data" such as governmental and private datasets, from average income to loan defaults to automated license place readers. Thus, African-American and Hispanic neighborhoods are computationally allocated more policing "resources" in a move that public officials consider to be bias-free and accountable because it is algorithmically determined (Brayne 2015). In a similar vein, Marion Fourcade and Kieran Healy (2013) examine the development of credit-worthiness scores using social media and purchasing traces to determine differential "life chances." Such inequalities are obscured by the popular premise of computational objectivity, yet are produced via sociotechnical systems that combine hegemonic ways of knowing, diverse political actors and institutions, systematic inequalities, and computationally-contingent social interventions.

Such contemporary scenarios call out for STS. Analysis of these and related sites is taking place in a variety of intersecting spaces associated with STS like sociology, information science, technology policy, media studies, and communications, and is deploying STS insights to produce important claims. However, this should not be a simple export process in which STS theories are assembled, piecemeal, to address topics of concern "elsewhere." We might see this "trading zone" instead as an opportunity to return to central questions, methods, and analytical approaches in the field. As such, work at these productive intersections concerns us all.

\section{Digital Methods}

The digital humanities and social sciences have rushed to embrace the tools and techniques of big data analytics, textual analysis, and machine learning. But few of these communities are putting much thought into the epistemological assumptions that come along with these tools. Of course, part of doing good social science is understanding the limitations of any given technique, method, or a dataset. But there is also the fundamental question of which epistemological commitments these 
contemporary and expanding computational techniques bring to the fore. Like all good epistemological questions there are political stakes in the mix. Such stakes are high both outside and within the academy, whether in the considerable dollars invested in data-rich startups or in the appeals to funding amid the computerization and quantification of the digital humanities.

Again the tools of STS are necessary to peer behind both the hype and the algorithms themselves, and perhaps to develop our own ways of knowing that both deploy these digital techniques and perhaps turn them around, back on themselves. This means, on the one hand, embracing what these tools can reveal about the production of knowledge. For instance, the domain of scientometrics is resurging in the era of "big data" (Evans and Foster 2011) and has much to offer in conversation with qualitative results (see Cambrosio et al. 2004). On the other hand, we might embrace digital tools that are themselves reflective of their shortcomings or that attempt to surface other forms of knowledge production in the course of data analytics.

Even our traditional methods like ethnography are being altered to accommodate digital interactions. One example is the "trace ethnography" method developed by Stuart Geiger and David Ribes to study Wikipedia communities, bots and vandals (2011), deploying the system's logs and traceable usernames to construct a picture of a slice of community interactions, while remaining critical as to the completeness of such "big data" records. In my own research group of five ethnographers, we also became concerned with our own differently-embodied, situated ways of knowledge construction as our ethnographies became increasingly distributed and networked. Putting our own partial perspectives into context helped us to better understand both the distributed science collaborations we studied and our own techniques of knowledge production. Such examples demonstrate how even classic techniques like ethnography may inspire renewed epistemological and methodological inquiry as our sites and our methods become increasingly networked, digitized, and distributed.

\section{Digital Interventions}

It was once the case that STS scholars would offer interventions and public scholarship through policy recommendations. Our appeals were to higher powers, our connections with legal frameworks and courts; or to activist groups, the communities we have studied in our attempts to capture how different kinds of knowledge matters. Alongside these engagements the digital sphere offers expanded opportunities for intervention and study, not simply through websites and public outreach initiatives, but also through design. Here, scholars are increasingly seeking to deploy concepts from the sociology of knowledge and of objects to subvert the typical 
assumptions embedded in devices, while proposing concrete, material alternatives. A bottom-up intervention into the very tools of knowledge production in our world, this style of critical design and making asks us to question how we know what we know, and then to wonder how we might know differently.

A variety of tools and methods circulate among an energetic community of makers and designers who deploy social critique in their work (among them Loukissas and Mindell 2012; Ratto et al. 2014; Forlano et al. 2012; Watts 2012). An evocative example is the Mechanical Turk subversion, "Turkopticon" by Lilly Irani and Six Silberman (2013). Turkopticon is a browser plugin that allows workers on the crowdsourcing site Amazon Mechanical Turk to observe and report on their bosses and provide backstage chatter to other Turkers about particular employers or tasks. The project takes a postcolonial and feminist approach to problems of digital labor including seeking to raise the visibility of the laborer's body and conditions, and attending to reproductions of global inequalities in labor hierarchies. In addition to the plugin, the researchers also foster a site of collected Turker haikus about their work, and are engaged in the kind of reflective practices essential to studying underprivileged communities. Thus, STS analysis of technologies and knowledge production inspired a technical intervention to subvert dominant assumptions, making the partial perspectives and subjugated knowledges that fuel this platform visible. Given that Amazon's Mechanical Turk is now a standard tool in psychological- and increasingly sociological-research, such interventions have implications for knowledge production as well. Further, the simplicity of this browser plugin script demonstrates that such projects need not be tremendously complex or expensive in order to be extraordinarily effective. Scholars can, therefore, have broad and wide-ranging impacts using digital tools and distribution methods beyond the book or the journal article through encouraging a kind of acting-with designed objects in the world.

\section{Looking Forward}

With the expansion of computing "off the desktop," we stand at the cusp of a novel set of challenges as our community addresses the production of knowledge in the contemporary context. Like prior generative overlaps with gender and sexuality studies, economic sociology, and postcolonial studies, these challenges require us to revisit, interrogate, and expand our theoretical, methodological, and practical toolkits. And like those prior overlaps, conversation between STS and digital studies can further break down assumptions about "natural" or static categories, practices, and tools that may otherwise be taken for granted, black boxed, or 
considered too obvious for study in the domain. In other words, digital systems considered symmetrically with other practices and tools provide renewed opportunities for theory-building and analysis, if we pay attention to how they intersect our sites of interest.

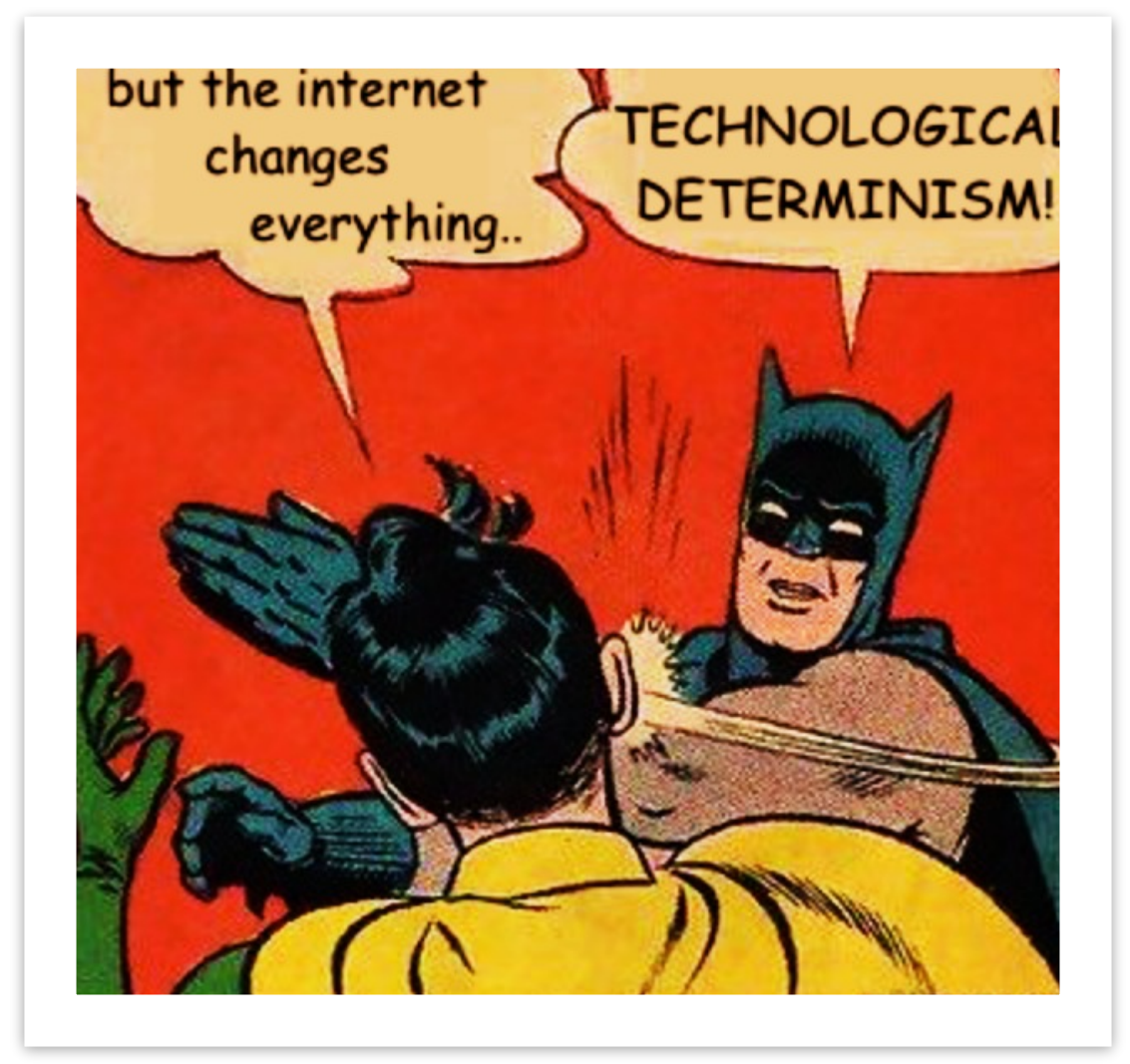

Figure 1. The author deploys an Internet "meme" (a meaningful found image, frequently with author-generated caption, spread widely online) to express how STS might approach the digital.

Some of this work is already underway. Scholars are deploying analysis of digital systems such as bots and robots to rethink our concept of technological agency, building upon and contributing to our contemporary theorizing in post-actor-network theory and relational ontology (Suchman 2006; Knorr-Cetina and Bruegger 2000). Others examine digital image work to return to classic themes of theory-laden observation (i.e. Coopmans 2011; Vertesi 2015) and 
representation in scientific practice (i.e. Carusi et al. 2014; Coopmans et al. 2014). And for the last four years I have worked with a growing movement among STS scholars and practitioners who share an interest in digital contextures as sites in which novel elements become perspicuous, to speak afresh to our community's analytical commitments. Indeed, my discussion here draws upon the rich understandings and framings that we have developed in conversation since 2011.

It is evidently not the case that "the digital changes everything." But the rich, evolving frameworks we have developed in science and technology studies need to be brought to bear more widely on the topic of information technology in daily life and in knowledge work. We must grapple with what it means to have lay-expert communication migrate onto online fora moderated by government agencies, and what it means to conduct science by conference call as well as to address questions of what happens when our own practices in the anthropology, sociology, and history of science, knowledge and technology "go digital." Our colleagues in related fields have taken up many of our scholars and our scholarship to explore and build digital systems; we must bring those conversations closer to home to help our own field develop the tools we need to examine digital sites within an STS frame. Let us, therefore, seize "the digital" as an essential site of empirical and methodological exploration for our field, and bring our critical perspective to these emerging intersections of knowledge production, of materials and methods, of infrastructures, networks, and expertise. Our scholarship, our attention, and our interventions are missing in the conversation: it is time to step up to the plate.

\section{Acknowledgements}

Many thanks to the digitalSTS community, especially David Ribes, Laura Forlano and Yanni Loukissas, whose conversation is invaluable for exploring these ideas; and to the Society for Social Studies of Science, NSF Sociotech Research Coordination Network, the Sloan Foundation, and Microsoft Research for supporting and making those conversations possible.

\section{References}

Beaulieu, A. 2010. "Research Note: From Co-Location to Co-Presence: Shifts in the Use of Ethnography for the Study of Knowledge." Social Studies of Science 40 (3): 453-70. doi: $10.1177 / 0306312709359219$

Berg, M. 1998. "The Politics of Technology: On Bringing Social Theory into Technological Design." Science Technology and Human Values 23 (4): 456-490. doi: $10.1177 / 016224399802300406$ 
Bietz, M., E. P. S. Baumer and C. P. Lee. 2010. "Synergizing in Cyberinfrastructure Development." Computer Supported Cooperative Work (CSCW) 19 (3-4): 245-81. doi:10.1007/ s10606-010-9114-y.

Boczkowski, P. J. 2004. Digitizing the News: Innovation in Online Newspapers. Cambridge, Mass.: MIT Press.

Bowker, G. and S. L. Star. 1999. Sorting Things Out: Classification and Its Consequences. Cambridge, M.A.: MIT Press.

Brayne, S. 2015. "Stratified surveillance: policing in the age of big data." Ph.D. Thesis, Department of Sociology, Princeton University, 2015.

Cambrosio, A., P. Keating and A. Mogoutov. 2004. "Mapping Collaborative Work and Innovation in Biomedicine: A Computer-Assisted Analysis of Antibody Reagent Workshops." Social Studies of Science 34 (3): 325-64. doi:10.1177 / 0306312704043767.

Carusi, A., A. S. Hoel, T. Webmoor and S. Woolgar. 2014. Visualization in the Age of Computerization. Studies in Science, Technology, and Society. New York: Routledge.

Coopmans, C. 2011. “'Face Value': New Medical Imaging Software in Commercial View." Social Studies of Science 41 (2): 155-76. doi:10.1177 / 0306312710389226.

Coopmans, C., J. Vertesi, M. Lynch and S. Woolgar. 2014. Representation in Scientific Practice Revisited. Cambridge, MA: MIT Press.

Dear, P. 2001. "Science Studies as Epistemography." In The One Culture, edited by H. M Collins and J. A. Labinger, 128-41. Chicago: Chicago University Press.

Edwards, P. N. 2013. A Vast Machine: Computer Models, Climate Data, and the Politics of Global Warming. Cambridge, MA: MIT Press.

Evans, J. A. and J. G. Foster. 2011. “Metaknowledge.” Science 331 (6018): 721-25. doi:10.1126/ science.1201765.

Forlano, L., D. Hannah, K. Jungnickel, J. McHardy and H. S. Rogers. (2012). “Experiments in (and out of) the studio: Art and design methods for Science and Technology Studies."

Retrieved from: https: / / www.academia.edu/2527061/

Experiments_in_and_out_of_the_studio_Art_and_design_methods_for_Science_and_Tec hnology_Studies_2012_

Fourcade, M. and K. Healy. 2013. "Classification situations: Life-chances in the neoliberal era. Accounting, Organizations and Society 38 (2013) 559-572 
Geiger, R. S. and D. Ribes. 2011. "Trace Ethnography: Following Coordination through Documentary Practices." In Proceedings of the 44th Hawaii International Conference on System Science, 1-10. doi:10.1109/HICSS.2011.455.

Gieryn, T. F. 2000. "A Space for Place in Sociology." Annual Review of Sociology 26: 463-96.

Gieryn, Tom F. 2002. "Three Truth-Spots." Journal of the History of the Behavioral Sciences 38 (2): 11332. doi:10.1002/jhbs.10036.

Gillespie, T., P. J. Boczkowski and K. A. Foot, eds. 2014. Media Technologies: Essays on Communication, Materiality, and Society. Inside Technology. Cambridge, Massachusetts: The MIT Press.

Hanson, N. R. 1958. Patterns of Discovery: An Inquiry into the Conceptual Foundations of Science. Cambridge: Cambridge University Press.

Haraway, D. 1988. "Situated Knowledges: The Science Question in Feminism and the Privilege of Partial Perspective." Feminist Studies 14 (3): 575-99. doi:10.2307/3178066.

Healey, K. and M. Fourcade. 2014.

Irani, L. and M. Silberman. 2013. "Turkopticon: Interrupting worker invisibility in amazon mechanical Turk." Proceedings of the SIGCHI Conference on Human Factors in Computing Systems. New York: ACM Press, 611-620.

Jackson, S. J., D. Ribes, A. Buyuktur and G. C. Bowker. 2011. “Collaborative Rhythm: Temporal Dissonance and Alignment in Collaborative Scientific Work." In Proceedings of the 2011 Conference on Computer-Supported Cooperative Work, 245-254. ACM Press. doi: 10.1145/1958824.1958861.

Jordan, K. and M. Lynch. 1998. "The Dissemination, Standardization and Routinization of a Molecular Biological Technique." Social Studies of Science 28 (5/6): 773-800.

Knorr Cetina, K. and U. Bruegger. 2000. "The Market as an Object of Attachment: Exploring Postsocial Relations in Financial Markets." Canadian Journal of Sociology 25 (2): 141-68.

Knorr-Cetina, K. 1999. Epistemic Cultures: How the Sciences Make Knowledge. Cambridge, Mass: Harvard University Press.

Knorr-Cetina, K., and A. Preda, eds. 2005. The Sociology of Financial Markets. Oxford; New York: Oxford University Press.

Kohler, R. 2002. Landscapes and Labscapes. Chicago: University of Chicago Press.

Latour, B. and S. Woolgar. 1979. Laboratory Life: The Construction of Scientific Facts. 1st ed. Princeton: Princeton University Press.

Latour, B. 1988. "Drawing Things Together." In Representation in Scientific Practice, edited by M. Lynch and S. Woolgar, 19-68. Cambridge, MA: MIT Press. 
Latour, B. 2004. "Which Politics for Which Artifacts?" Domus.

Lewenstein, B. 1995. "Science and the Media." In Handbook of Science and Technology Studies, edited by S. Jasanoff, G. Markle, J. Peterson, and T. Pinch, 1st edition, 343-60. Thousand Oaks, Calif: Sage Publications.

Loukissas, Y. and D. Mindell. 2014. “Visual Apollo: A Graphical Exploration of Computer-Human Relationships." Design Issues 30 (2): 4-16.

Lynch, M. 2013. "Ontography: Investigating the Production of Things, Deflating Ontology." Social Studies of Science 43 (3): 444-62. doi:10.1177 / 0306312713475925.

Lynch, M., S. Cole, R. McNally and K. Jordan. 2008. Truth Machine: The Contentious History of DNA Fingerprinting. Chicago: University of Chicago Press.

Lynch, M. 1991. "Laboratory Space and the Technological Complex: An Investigation of Topical Contextures." Science in Context 4 (1): 51-78.

Lynch, M. 1993. Scientific Practice and Ordinary Action: Ethnomethodology and Social Studies of Science. Cambridge, UK: Cambridge University Press.

MacKenzie, D. A. 2006. An Engine, Not a Camera: How Financial Models Shape Markets. Inside Technology. Cambridge, MA: MIT Press.

Marcus, G. E. 1995. "Ethnography In/of the World System: The Emergence of Multi-Sited Ethnography." Annual Review of Anthropology 24: 95-117.

Merton, R. 1942. "The Normative Structure of Science." In The Sociology of Science: Theoretical and Empirical Investigations, edited by N. W. Storer, 267-78. Sociology of Science in Europe.. Chicago: University of Chicago Press.

Millerand, F., D. Ribes, K. S. Baker and G. C. Bowker. 2013. "Making an Issue out of a Standard: Storytelling Practices in a Scientific Community." Science, Technology \& Human Values 38 (1): 7-43. doi:10.1177/0162243912437221.

Ratto, M., S. Wylie and K. Jalbert. 2014. "Introduction to the Special Forum on Critical Making as Research Program." The Information Society 30(2): 85-95.

Ribes, D. and G. C. Bowker. 2008. "Organizing for Multidisciplinary Collaboration: The Case of the Geosciences Network." In Scientific Collaboration on the Internet, edited by G. M. Olson, A. Zimmerman and N. Bos, 310-30. Cambridge, MA: MIT Press.

Star, S. L. and K. Ruhleder. 1994. “Steps Towards an Ecology of Infrastructure: Complex Problems in Design and Access for Large-Scale Collaborative Systems." In: Proceedings of the ACM conference on Computer supported cooperative work. New York: ACM Press, 253-264. 
Star, S. L. and J. R. Griesemer. 1998. "Institutional Ecology, 'Translations,' and Boundary Objects: Amateurs and Professionals in Berkeley's Museum of Vertebrate Zoology, 1907-39." In The Science Studies Reader, edited by M. Biagioli, 505-24. New York: Routledge.

Star, S. L. 2010. "This Is Not a Boundary Object: Reflections on the Origin of a Concept." Science, Technology \& Human Values 35 (5): 601-17. doi:10.1177/0162243910377624.

Stark, D. 2009. The Sense of Dissonance: Accounts of Worth in Economic Life. Princeton: Princeton University Press.

Suchman, L. 1987. Plans and Situated Actions: The Problem of Human-Machine Communication. Cambridge: Cambridge University Press.

Suchman, L. 2006. Human-Machine Reconfigurations: Plans and Situated Actions. 2nd ed. Cambridge: Cambridge University Press. http://ebooks.cambridge.org/ref/id/ CBO9780511808418.

Vertesi, J. 2014. "Seamful Spaces: Heterogeneous Infrastructures in Interaction." Science, Technology \& Human Values 39 (2): 264-84. doi:10.1177 / 0162243913516012.

Vertesi, J. 2015. Seeing like a Rover: How Robots, Teams, and Images Craft Knowledge of Mars. Chicago: University of Chicago Press.

Winner, L. 1986. "Do Artifacts Have Politics?” In The Whale and the Reactor: A Search for Limits in an Age of High Technology, 19-39. Chicago: University of Chicago Press.

Woolgar, S. and G. Cooper. 1999. “Do Artefacts Have Ambivalences?: Moses' Bridges, Winner's Bridges, and Other Urban Legends in S\&TS." Social Studies of Science 29 (3): 433-49.

Woolgar, S. 1990. "Configuring the User: The Case of Usability Trials." The Sociological Review 38 (S1): 58-99. doi:10.1111/j.1467-954X.1990.tb03349.x. 